\title{
Natural variation in virulence of the entomopathogenic fungus Beauveria bassiana against malaria mosquitoes
}

\author{
Claudio A Valero-Jiménez ${ }^{1,2^{*}}$, Alfons JM Debets ${ }^{1}$, Jan AL van Kan ${ }^{3}$, Sijmen E Schoustra', Willem Takken²,
} Bas J Zwaan ${ }^{1}$ and Constantianus JM Koenraadt ${ }^{2}$

\begin{abstract}
Background: Insecticide resistance is greatly hampering current efforts to control malaria and therefore alternative methods are needed. Entomopathogenic fungi have been proposed as an alternative with a special focus on the cosmopolitan species Beauveria bassiana. However, few studies have analysed the effects of natural variation within fungal isolates on mosquito survival, and the implications and possible exploitation for malaria control.

Methods: Laboratory bioassays were performed on adult female mosquitoes (Anopheles coluzzii) with spores from 29 isolates of B. bassiana, originating from different parts of the world. In addition, phenotypic characteristics of the fungal isolates such as sporulation, spore size and growth rate were studied to explore their relationship with virulence.

Results: All tested isolates of B. bassiana killed An. coluzzii mosquitoes, and the rate at which this happened differed significantly among the isolates. The risk of mosquitoes dying was around ten times higher when they were exposed to the most virulent as compared to the least virulent isolate. There was significant variation among isolates in spore size, growth rate and sporulation, but none of these morphological characteristics were correlated, and thus predictive, for the ability of the fungal isolate to kill malaria mosquitoes.

Conclusions: This study shows that there is a wide natural variation in virulence of isolates of B. bassiana, and that selecting an appropriate fungal isolate is highly relevant in killing and thus controlling malaria mosquitoes, particularly if used as part of an integrated vector management strategy. Also, the wide variation observed in virulence offers the opportunity to better understand the molecular and genetic mechanisms that drive this variation and thus to address the potential development of resistance against entomopathogenic fungi.
\end{abstract}

Keywords: Entomopathogenic fungi, Beauveria bassiana, Vector control, Virulence

\section{Background}

Although globally malaria mortality rates have fallen by $45 \%$ between 2000 and 2012, malaria is still killing an estimated 627,000 people each year [1]. An effective way to alleviate the burden of malaria is to control its vector (anopheline mosquitoes) using insecticides. This can be achieved either through the use of insecticide-treated bed nets (ITNs) or through indoor residual spraying of

\footnotetext{
* Correspondence: claudio.valero@wur.nl

'Laboratory of Genetics, Wageningen University, P.O Box 309, 6700, AH

Wageningen, The Netherlands

${ }^{2}$ Laboratory of Entomology, Wageningen University, P.O. Box 8031, 6700, EH

Wageningen, The Netherlands

Full list of author information is available at the end of the article
}

insecticides (IRS). However, because of rapidly expanding insecticide resistance, there is a need to find alternatives to control the mosquitoes [1]. Entomopathogenic fungi have been proposed as novel biological control agent to kill malaria mosquitoes [2-4]. Such fungi have already been used on a wide scale to control beetles [5], locusts [6] and other pest insects in agriculture.

Spores of hypocrealean entomopathogenic fungi are able to infect insects, including mosquitoes, via attachment to the insect's epicuticle [7]. Spores will penetrate the insect's cuticle by forming a germ tube and appressorium. The latter structure uses mechanical pressure and produces cuticledegrading enzymes for further penetration $[8,9]$. Once the 
fungal structures reach the haemocoel, they are able to use the insect nutrients and grow. If the fungi are able to overcome the host immune defences, the host will die and saprophytic growth starts subsequently from the dead host. Finally, sporulation of the fungus takes place a few days later, depending on environmental conditions [10].

More specifically, the hypocrealean entomopathogenic fungi Beauveria bassiana and Metarhizium anisopliae can reduce the lifespan of mosquitoes under laboratory and field conditions [11], and they are also equally effective in killing insecticide-resistant mosquitoes [12-14]. Besides the lethal effects, fungal infections reduce rodent Plasmodium sporozoite levels [15], female fecundity and feeding propensity $[16,17]$. Most likely, the latter is the result of entomopathogenic fungi that reduce the hostseeking behaviour of mosquitoes by lowering the response of olfactory receptor neurons exposed to odour cues, as demonstrated for Anopheles stephensi [18].

Entomopathogenic fungi kill mosquitoes relatively slowly compared to insecticides (1-2 weeks vs 1-2 days). This is potentially beneficial for controlling malaria, because the Plasmodium development time in the mosquito is about ten to 14 days [19]. Because of the delayed mortality, fungal pathogens specifically kill those mosquitoes that are old enough to transmit the parasite. Therefore, the selective pressure for survival in mosquitoes is reduced, and thus, the probability of developing resistance against fungal infections is much lower [20].

Beauveria bassiana is a cosmopolitan fungus from which more than thousand isolates have been collected from different locations and different points in time worldwide [21]. Phylogenetic analysis has revealed at least 18 different clades (S A Rehner, pers comm). However, to date it is not clear how much these fungal isolates vary in their ability to kill mosquitoes. The majority of mosquito control studies has focused on one isolate, namely IMI 391510 [12,17,22,23] (except Blanford et al. [15]). It is important to study the natural variation of virulence against mosquitoes because this has an impact on the choices for selecting the optimal fungal agents for controlling malaria vectors and other mosquitoes and their diseases. The natural occurring variation in virulence can also be used to uncover the mechanisms that underpin it, which will allow the estimation of the potential for resistance development in the vector. For example, the whole genome of isolates with contrasting variation in virulence could be sequenced, and pairwise polymorphisms, deletions and Single Nucleotide Polymorphisms (SNPs) in structural and regulatory parts of genes could be analysed. Furthermore, transcriptome analysis of contrasting isolates could be performed, and linking the DNA-sequence variation to variation in gene expression could provide unique data on the fungal genes involved in insect infection and the molecular genetic mechanisms which influence virulence. This, in turn, will increase the potential for the development of entomopathogenic fungi as a biological control method against mosquitoes.

On the other hand, previous studies have shown that morphological and physiological characteristics of fungi are related to their virulence, such as hyphal growth rate, conidial viability, conidia production, conidia size, enzyme secretion among other factors [24-28]. For instance, fungal isolates with rapid germination and high hyphal growth rate could be desirable because such fungi could infect the host more rapidly [24]. Such characteristics could be used as criteria for isolate selection in addition to their virulence towards mosquitoes.

Therefore, in the current study, the virulence of 29 isolates of $B$. bassiana was evaluated on the malaria mosquito Anopheles coluzzii (formerly: Anopheles gambiae sensu stricto). Phenotypic characteristics of the fungal isolates such as sporulation, spore size and growth rate were measured and their correlation with virulence analyzed.

\section{Methods \\ Mosquito rearing}

Anopheles coluzzii mosquitoes used in the experiments originated from Suakoko, Liberia (courtesy of the late Prof M Coluzzi). Larvae were reared in plastic trays of $10 \times 25 \times 8 \mathrm{~cm}$, filled with $1 \mathrm{l}$ of tap water at densities of approximately 0.3 larvae $/ \mathrm{cm}^{2}$. Larvae were fed on Tetramin $^{\circledR}$ fish food (Tetra A G, Melle, Germany) daily, using $0.1 \mathrm{mg} /$ larva for first instar larvae and $0.3 \mathrm{mg} /$ larva for the other three larval stages. Pupae were collected daily and transferred to holding cages of $30 \times 30 \times 30 \mathrm{~cm}$ in which adults were maintained in climate controlled rooms $\left(27 \pm 1^{\circ} \mathrm{C}, 80 \pm 10 \% \mathrm{RH}\right.$ and a $\left.12 \mathrm{hr} \mathrm{L}: \mathrm{D}\right)$ and fed ad libitum on a $6 \%$ glucose solution.

\section{Production of Beauveria bassiana}

All isolates of $B$. bassiana used in this study were obtained from the USDA-ARS Collection of Entomopathogenic Fungal Cultures (ARSEF) (Table 1) except for isolate IMI 391510, which was kindly provided by the Bioprocess Engineering Department (Wageningen University, The Netherlands). Isolates were selected randomly from the ARSEF collection taking into account a wide geographical distribution as well as a broad array of hosts, including isolates that were found in soil. Initially the fungi were grown on Sabouraud Dextrose Agar with $1 \%$ yeast extract (SDAY) for 14 days at $27^{\circ} \mathrm{C}$ and spores were harvested with a $0.05 \%$ Tween 80 solution to make a spore suspension and kept at $-80^{\circ} \mathrm{C}$ until used.

To have sufficient spores for the experiments, all isolates were grown on solid-state fermenters, with a final yield of around 1-3 g of air-dry spores per isolate. In 
Table 1 Details of the tested Beauveria bassiana isolates against Anopheles coluzzii, including information from which host insect it was isolated, geographic origins and morphological characteristics

\begin{tabular}{|c|c|c|c|c|c|}
\hline Isolate $^{1}$ & Host insect & Geographic origins & Size $(\mu \mathrm{m})( \pm$ SEM) & $\begin{array}{l}\text { Growth } \\
\text { (mm/day) } \\
( \pm \text { SEM) }\end{array}$ & $\begin{array}{l}\text { Sporulation } \\
\left.\text { ( } 10^{6} \text { conidia/ } \mathrm{cm}^{2}\right) \\
( \pm S E M)\end{array}$ \\
\hline ARSEF 220 & & Commonwealth of Independent States & $2.57( \pm 0.02)$ & $2.22( \pm 0.01)$ & $3.42( \pm 1.79)$ \\
\hline ARSEF 502 & $\begin{array}{l}\text { Lepidoptera; Pyralidae; Ostrinia } \\
\text { nubilalis }\end{array}$ & China & $2.75( \pm 0.03)$ & $2.38( \pm 0.01)$ & $9.75( \pm 0.32)$ \\
\hline ARSEF 714 & $\begin{array}{l}\text { Homoptera; Delphacidae; } \\
\text { Nilaparvata lugens }\end{array}$ & China: Wuhan, Hupei & $2.34( \pm 0.00)$ & $2.54( \pm 0.07)$ & $14.69( \pm 2.00)$ \\
\hline ARSEF 721 & $\begin{array}{l}\text { Coleoptera; Chrysomelidae; } \\
\text { Diabrotica sp. }\end{array}$ & Colombia: Cali, Valle del Cauca & $2.45( \pm 0.03)$ & $2.14( \pm 0.02)$ & $4.75( \pm 1.63)$ \\
\hline ARSEF 1149 & $\begin{array}{l}\text { Lepidoptera; Noctuidae; } \\
\text { Helicoverpa armigera }\end{array}$ & Spain: Córdoba & $2.47( \pm 0.02)$ & $2.36( \pm 0.05)$ & $16.52( \pm 1.07)$ \\
\hline ARSEF 1514 & $\begin{array}{l}\text { Diptera; Muscidae; Musca } \\
\text { autumnalis }\end{array}$ & France: Le Trait, Seine-Maritime & $2.52( \pm 0.03)$ & $1.85( \pm 0.03)$ & $1.51( \pm 0.36)$ \\
\hline ARSEF 1520 & Hemiptera; Miridae; Lygus sp. & France: Prades, Pyrénées-Orientales & $2.45( \pm 0.01)$ & $2.41( \pm 0.02)$ & $6.83( \pm 0.36)$ \\
\hline ARSEF 1816 & $\begin{array}{l}\text { Coleoptera; Curculionidae; } \\
\text { Sitona discoideus }\end{array}$ & Morocco: Hauteban & $2.49( \pm 0.02)$ & $2.45( \pm 0.01)$ & $31.72( \pm 9.84)$ \\
\hline ARSEF 2075 & $\begin{array}{l}\text { Coleoptera; Chrysomelidae; } \\
\text { Ceratoma arcuata }\end{array}$ & Brazil: Ribeira do Pombal, Bahia & $2.55( \pm 0.01)$ & $2.45( \pm 0.03)$ & $9.37( \pm 2.12)$ \\
\hline ARSEF 2427 & $\begin{array}{l}\text { Homoptera; Delphacidae; } \\
\text { Nilaparvata lugens }\end{array}$ & Indonesia: Cikampek, Java Barat, Java & $2.40( \pm 0.01)$ & $2.60( \pm 0.02)$ & $24.64( \pm 4.28)$ \\
\hline ARSEF 2571 & $\begin{array}{l}\text { Lepidoptera; Lymantriidae; } \\
\text { Lymantria dispar }\end{array}$ & USA: Delaware & $2.39( \pm 0.02)$ & $2.23( \pm 0.08)$ & $13.46( \pm 1.93)$ \\
\hline ARSEF 2597 & $\begin{array}{l}\text { Lepidoptera; Hyblaeidae; } \\
\text { Hyblaea puer }\end{array}$ & India & $2.37( \pm 0.01)$ & $2.26( \pm 0.01)$ & $3.02( \pm 0.31)$ \\
\hline ARSEF 2861 & $\begin{array}{l}\text { Homoptera; Aphididae; } \\
\text { Diuraphis noxia }\end{array}$ & USA: Parma, Idaho & $2.38( \pm 0.01)$ & $2.19( \pm 0.05)$ & $4.16( \pm 1.09)$ \\
\hline ARSEF 4135 & $\begin{array}{l}\text { Coleoptera; Scarabaeidae; } \\
\text { Adoryphorus coulonii }\end{array}$ & Australia: Newtown, Tasmania & $2.47( \pm 0.01)$ & $2.30( \pm 0.05)$ & $1.97( \pm 0.62)$ \\
\hline ARSEF 4305 & Soil & Australia: Epping Forest, Tasmania & $2.43( \pm 0.02)$ & $2.46( \pm 0.09)$ & $14.74( \pm 1.78)$ \\
\hline ARSEF 4396 & Soil & Japan: Sapporo, Hokkaido & $2.37( \pm 0.02)$ & $2.71( \pm 0.02)$ & $23.11( \pm 0.54)$ \\
\hline ARSEF 4672 & $\begin{array}{l}\text { Lepidoptera; Hepialidae; } \\
\text { Oncopera intricata }\end{array}$ & Australia: Plenty, Tasmania & $2.23( \pm 0.01)$ & $2.08( \pm 0.02)$ & $1.08( \pm 0.08)$ \\
\hline ARSEF 5078 & $\begin{array}{l}\text { Lepidoptera; Pyralidae; } \\
\text { Galleria mellonella }\end{array}$ & USA: Grayland, Washington & $2.41( \pm 0.03)$ & $2.34( \pm 0.07)$ & $2.83( \pm 0.44)$ \\
\hline ARSEF 5641 & $\begin{array}{l}\text { Orthoptera; Acrididae; } \\
\text { Schistocerca gregaria }\end{array}$ & Ethiopia: Eritrea, Shelsela & $2.20( \pm 0.01)$ & $2.27( \pm 0.03)$ & $3.03( \pm 0.96)$ \\
\hline ARSEF 5642 & $\begin{array}{l}\text { Orthoptera; Acrididae; } \\
\text { Schistocerca gregaria }\end{array}$ & Ethiopia: Eritrea, Shelsela & $2.20( \pm 0.02)$ & $2.16( \pm 0.03)$ & $5.08( \pm 0.68)$ \\
\hline ARSEF 5769 & $\begin{array}{l}\text { Homoptera; Adelgidae; } \\
\text { Adelges tsugae }\end{array}$ & USA: Lovingston, Virginia & $2.23( \pm 0.01)$ & $1.79( \pm 0.05)$ & $24.82( \pm 5.89)$ \\
\hline ARSEF 6686 & Coleoptera; Scarabaeidae & Ethiopia: Tikur Inchini, Western Shoa & $2.46( \pm 0.01)$ & $2.04( \pm 0.03)$ & $4.83( \pm 1.26)$ \\
\hline ARSEF 6907 & $\begin{array}{l}\text { Isoptera; Rhinotermitidae; } \\
\text { Coptotermes formosanus }\end{array}$ & USA: Lake Charles, Louisiana & $1.95( \pm 0.01)$ & $2.45( \pm 0.05)$ & $10.29( \pm 1.51)$ \\
\hline ARSEF 8028 & $\begin{array}{l}\text { Hemiptera: Anthocoridae, } \\
\text { Anthocoris nemorum }\end{array}$ & $\begin{array}{l}\text { Denmark: Bakkegården, Copenhagen, } \\
\text { Tåstrup, Zealand }\end{array}$ & $2.26( \pm 0.01)$ & $1.77( \pm 0.03)$ & $0.74( \pm 0.08)$ \\
\hline ARSEF 8034 & $\begin{array}{l}\text { Lepidoptera; Pyralidae; } \\
\text { Galleria mellonella }\end{array}$ & $\begin{array}{l}\text { Denmark: Bakkegården, Copenhagen, } \\
\text { Tåstrup, Zealand }\end{array}$ & $2.62( \pm 0.05)$ & $1.77( \pm 0.06)$ & $0.97( \pm 0.28)$ \\
\hline ARSEF 8414 & $\begin{array}{l}\text { Coleoptera; Cerambycidae, } \\
\text { Anoplophora glabripennis }\end{array}$ & China: Wuhe, Anhui & $2.28( \pm 0.02)$ & $2.27( \pm 0.10)$ & $8.78( \pm 0.82)$ \\
\hline ARSEF 8854 & $\begin{array}{l}\text { Coleoptera; Scarabaeidae. } \\
\text { Rhopaea magnicornis }\end{array}$ & Australia: Condong, New South Wales & $2.48( \pm 0.03)$ & $2.86( \pm 0.07)$ & $13.44( \pm 3.37)$ \\
\hline ARSEF 9595 & Hymenoptera; Apoidea & China: Guizhou Province & $2.55( \pm 0.02)$ & $1.65( \pm 0.10)$ & $0.35( \pm 0.07)$ \\
\hline IMI 391510 & Coleoptera: Chrysomelidae & USA & $2.34( \pm 0.01)$ & $2.37( \pm 0.07)$ & $6.82( \pm 0.84)$ \\
\hline
\end{tabular}

${ }^{1}$ ARSEF: USDA-ARS Collection of Entomopathogenic Fungal Cultures, USA. IMI: CABI Bioscience, UK. 
brief, $50 \mathrm{~g}$ hemp was weighed and $200 \mathrm{ml}$ of distilled water was added, mixed and sterilized for $30 \mathrm{~min}$ at $121^{\circ} \mathrm{C}$. Then $10 \mathrm{~g}$ of peptone and yeast extract were added and sterilized again. Once this mixture was cold, $200 \mathrm{ml}$ of a pre-autoclaved solution of glucose $(36.5 \mathrm{w} / \mathrm{w} \%)$ was added. This mixture was inoculated with $1 \mathrm{ml}$ of spore suspension $\left(1 \times 10^{8}\right.$ spores $\left./ \mathrm{ml}\right)$. It was incubated overnight at room temperature on a roller-bank. Then, the hemp was transferred into a 0.21 glass tube $(4.6 \mathrm{~cm}$ diameter; $30 \mathrm{~cm}$ height) and placed in a climate chamber set at $25^{\circ} \mathrm{C}$. After 21 days, spores were dried for four days by blowing dry air through the glass tube that contained the mixture. Spores were then harvested with sieves of various sizes $(125 \mu \mathrm{m}$ $1 \mathrm{~mm}$ ), and stored in $50 \mathrm{ml}$ tubes. The spores were kept at $4^{\circ} \mathrm{C}$ in the dark prior to use.

\section{Bioassays}

The virulence of 29 isolates of B. bassiana was checked by doing seven bioassays. Between three and six isolates were simultaneously compared in each bioassay. The seventh bioassay included four randomly chosen isolates to check for temporal experimental variation. In every bioassay, fungal spores of each isolate were suspended in Shellsol $\mathrm{T}^{\bullet}$ oil (Shell, The Netherlands) and standardized to $1 \times 10^{9}$ spores/ml by adjusting spore concentration after counting the suspension with a Bürker-Türk counting chamber. Spore viability was checked on SDAY plates after $18-20 \mathrm{hrs}$ at $27^{\circ} \mathrm{C}$, and spores with a detectable germ tube were considered viable. Of the standardized spore solution, $0.9 \mathrm{ml}$ was applied to an A4-sized proofing paper one day before exposure. Coated papers were left to dry in a fume hood [29]. These papers were then placed in PVC tubes $(15 \mathrm{~cm}$ height and $8 \mathrm{~cm}$ diameter) and sealed with cling film on both ends. For each isolate tested, three PVC tubes (replicates) were prepared in this way. As a control, papers were coated with Shellsol $\mathrm{T}^{\circ}$ oil only. Thirty An. coluzzii female mosquitoes (3-5 days old) were transferred with an aspirator to each PVC tube with the coated papers and exposed for three hours. After this, mosquitoes were transferred to plastic buckets (25 cm height and $20 \mathrm{~cm}$ diameter), which were sealed with a nylon sock. All buckets were kept in a climate controlled chamber $\left(27 \pm 1^{\circ} \mathrm{C}, 80 \pm 10 \% \mathrm{RH}, 12 \mathrm{~h} \mathrm{~L}\right.$ :D), and daily mortality was checked for 14 days. Mosquitoes were fed ad libitum with a $6 \%$ glucose solution on a cotton plug. Fungal infection of dead mosquitoes was checked by dipping them for $5 \mathrm{sec}$ in $70 \%$ ethanol, incubating them on moist filter paper in sealed petri dishes at $25^{\circ} \mathrm{C}$ for five to seven days, and inspecting them for visible fungal growth.

\section{Phenotypic characterization of fungal isolates}

To determine spore size, isolates were grown on SDAY petri dishes for 14 days and spores were harvested with a $0.05 \%$ Tween 80 solution to make a spore suspension. A 1:50 dilution was made and size was measured for four replicates per fungal isolate with a Coulter Counter Z2 (Beckman Coulter). Linear growth rate was measured using 'race tubes' [30]. The tubes were filled with $23 \mathrm{ml}$ of SDAY medium. Three tubes were inoculated for each isolate and growth was measured every week for three months. To determine sporulation, spores were harvested from a 14-day-old culture on SDAY with 0.05\% Tween 80 solution and counted on a haemocytometer chamber using an optical microscope (400X). Two areas of $1 \mathrm{~mm}^{2}$ were counted for each plate, and three plates in total were counted for each isolate.

\section{Statistical analysis}

Mosquito survival was analysed using Kaplan-Meier survival analysis in SPSS (v.19) with significant differences between different isolates estimated using a Log Rank Test. Differences between the control and the infected mosquitoes were examined using a Cox Regression analysis in SPSS. Hazard ratios (HR; the daily chance of death) in comparison with the isolate IMI391510 were calculated. One-way ANOVA was conducted in R (2.12.2) to detect differences in conidia size, sporulation and linear growth rate, with the sporulation data being Log transformed before analysis. A General Lineal Model was used to analyse the correlation between phenotypic characteristics of isolates and their virulence on mosquitoes using $R$ (2.12.2). To further check for any correlation among the phenotypic characteristics themselves, a Pearson's Correlation analysis was done. Mosquito survival exposed to the same fungal isolates at different time points were analysed using Kaplan-Meier survival analysis in SPSS (v.19) and significant differences were estimated using a Log Rank Test.

\section{Results}

\section{Bioassays on Anopheles coluzzii}

All B. bassiana isolates tested were pathogenic to An. coluz$z i i$ with mortalities of at least $92.5 \%$ by day 14 (Figure 1 ). Survival curves for all mosquitoes infected with the fungus were significantly different from the respective controls for each of the seven bioassays (Figure 1). Furthermore, 74$100 \%$ of the dead mosquitoes that were exposed to funguscoated paper showed evidence of fungal infection in the form of sporulation after five to seven days. The viability of fungal conidia of each fungal isolate was always higher than $70 \%$ at the start of the experiment. Although all bioassays were conducted in the same manner, not all controls behaved similarly in all bioassays. For unknown reasons, control mosquitoes from bioassay 1 and 3 had a significantly higher mortality compared to the controls from the other five bioassays $(\mathrm{F}=96.09$, d.f. $=6, \mathrm{p}<0.001$; Figure $1 \mathrm{~A}, 1 \mathrm{C})$. 


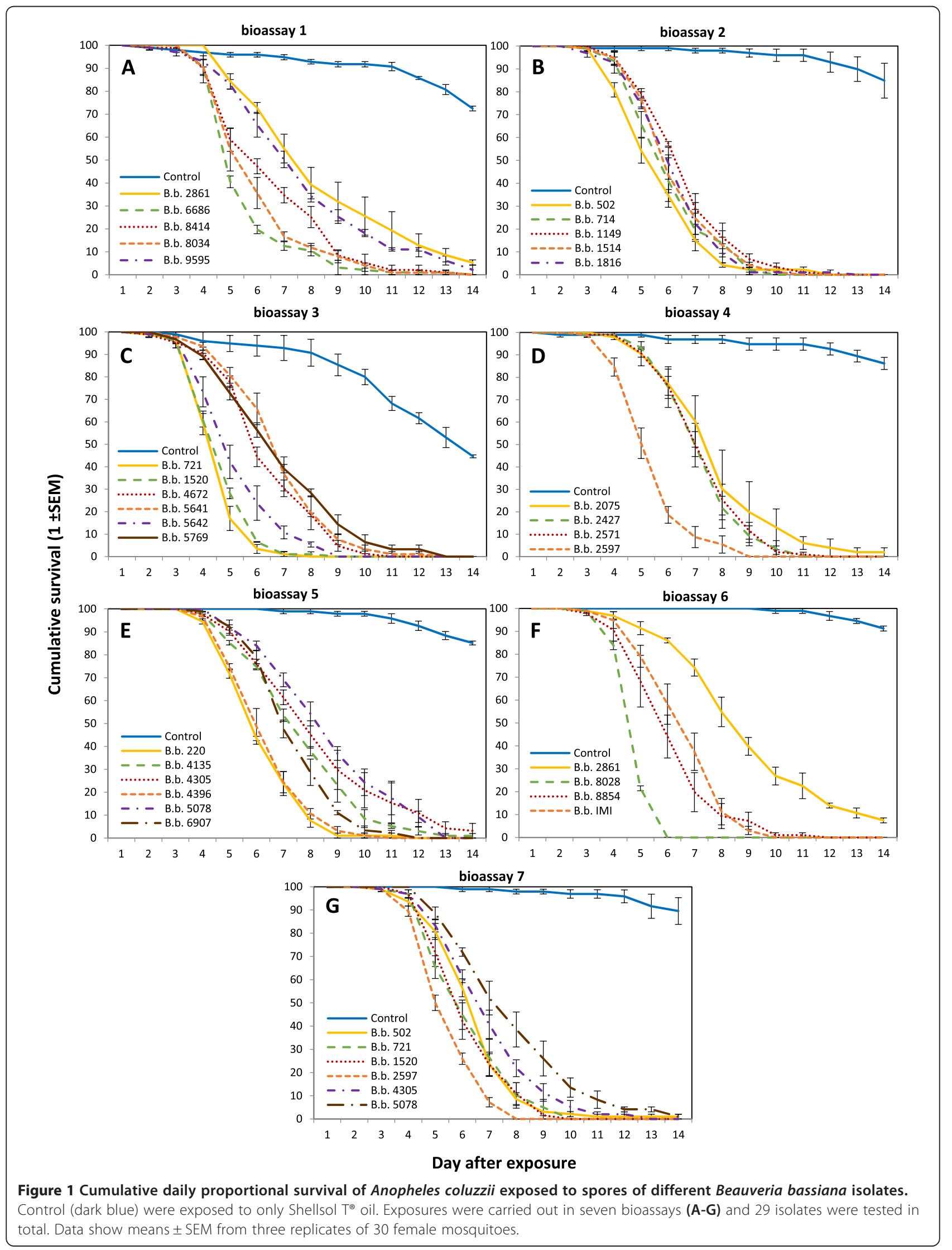


Therefore, these two bioassays were not considered for further analysis.

Hazard ratios (HR) were estimated relative to the mortality pattern of the reference isolate, IMI391510. This isolate was tested in detail during earlier laboratory and field trials [11,23], and thus constituted a relevant reference point. Virulence was classified in three groups: (1) isolates for which the HR was significantly higher than the HR of the reference isolate (these were termed 'highly lethal' (HL)); (2) isolates that were not significantly different compared the reference isolate (these were termed 'lethal' (L)); and, (3) fungal isolates that had significantly lower HR than the reference isolate (these were termed 'slightly lethal' (SL)). The majority of the 29 isolates was classified as lethal, although at least three were HL isolates and five were SL isolates (Figure 2). Virulence varied widely, as depicted by the extremes: isolate 8028 was on average 3.7 times more virulent and isolate 2861 was on average 2.7 times less virulent than the reference isolate IMI391510. All of these isolates (8028, IMI391510 and 2861) were tested within the same bioassay (Figure 1F) removing any possibility of temporal bias.

Isolates 502, 2597, 4305, and 5078 were randomly selected for the seventh bioassay to assess the presence of temporal variation in virulence. The two replicates of 2597 and 5078 were not significantly different from each other between the two time points and therefore were

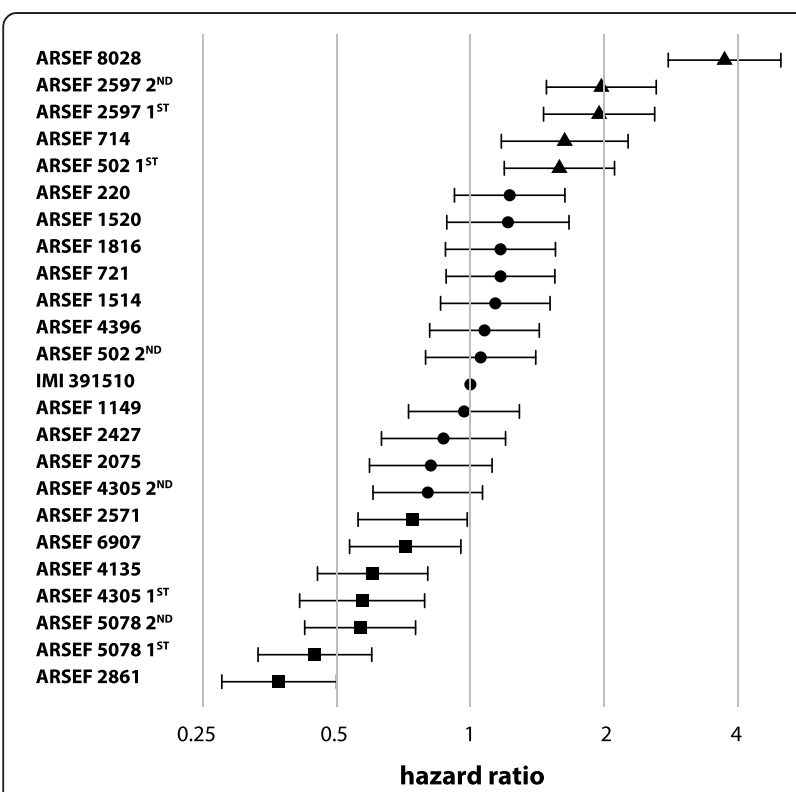

Figure 2 Hazard ratios for fungal infection using isolate IMI391510 as a baseline. Dot symbols represent the isolates that were not significantly different from the reference isolate IMI391510. Triangle/square symbols show isolates that were more/less virulent than the reference isolate. Whiskers represent the $95 \% \mathrm{Cls} .1^{\text {st }}$ or $2^{\text {nd }}$ indicates the result of the first or second biological replicate of an isolate. classified in the same virulence group (HL and SL, respectively). However, isolates 502 and 4305 showed significantly different $\mathrm{HR}$ between the temporal replicates $\left(x^{2}=10.33\right.$, d.f. $=1, \mathrm{p}=0.001 ; x^{2}=6.56$, d.f. $=1, \mathrm{p}=$ 0.010 ), and thus, their virulence status changed. Isolate 502 was considered HL in the first trial, and then L in the second trial. The opposite effect was observed for isolate 4305 .

\section{Phenotypic characterization of fungal isolates}

Conidia of the 29 isolates of $B$. bassiana had significant differences in size, ranging from 1.95 to $2.75 \mu \mathrm{m}(\mathrm{F}=$ 67.33 , d.f. $=28, \mathrm{p}<0.0001$, Table 1$)$. Conidia of isolates 502 and 8034 were the largest in size, whereas conidia of isolate 6907 were the smallest. Sporulation ranged from $3.5 \times 10^{5}$ to $3.17 \times 10^{7}$ spores $/ \mathrm{cm}^{2}$, and growth rate from 1.77 to $2.71 \mathrm{~mm} /$ day, with isolates differing significantly for both traits $(\mathrm{F}=10.08$, d.f. $=28, \mathrm{p}<0.0001$, and $\mathrm{F}=$ 11.48 , d.f. $=28, \mathrm{p}<0.0001$, respectively). The isolate that grew fastest was 4396 and the isolate that produced the most conidia was 1816. Nevertheless, none of these phenotypic characteristics of $B$. bassiana that were studied were correlated to the ability to kill malaria mosquitoes (i.e. virulence): sporulation $(\mathrm{F}=1.17$, d.f. $=28, \mathrm{p}=$ $0.791)$, growth rate $(\mathrm{F}=25.47$, d.f. $=28, \mathrm{p}=0.195)$ and spore size $(\mathrm{F}=22.74$, d.f. $=28, \mathrm{p}=0.169)$. Additionally, a Pearson's Correlation analysis was performed to further check for correlation among the phenotypic characteristics themselves, but none was found, except for a positive correlation between grow rate and sporulation $(\mathrm{r}=$ 0.704, $\mathrm{p}<0.001)$.

\section{Discussion}

Under laboratory conditions, all 29 tested isolates of $B$. bassiana killed An. coluzzii mosquitoes, although the rate at which this happened differed significantly among the isolates. The daily risk of death for mosquitoes when exposed to the most virulent isolate was around ten times higher than when exposed to the least virulent isolate. This observation is a substantial addition to a previous smaller scale study which tested six isolates of $B$. bassiana and two isolates of Metarhizium anisopliae against Anopheles stephensi mosquitoes [15]. In that study, of two isolates of $M$. anisopliae tested, only one was pathogenic to mosquitoes. Similarly, from six B. bassiana isolates, one was not pathogenic whereas the others had different rates of virulence.

Much progress has been made regarding the feasibility of using entomopathogenic fungi as a biological control agent for malaria mosquitoes. However, researchers have thus far overlooked the potential of selecting the most suitable isolate from the existing natural variation in fungal characteristics. From the study by Blanford et al. [15] onwards, isolate IMI391510 was selected in further 
experiments. This was based on practical considerations and not necessarily because it was the most virulent towards mosquitoes. For instance, this isolate was already evaluated and received regulatory approval for the control of other insects under field conditions. Follow-up studies mostly focused on isolate IMI391510 only or other isolates of $M$. anisopliae. These studies managed to standardize and improve their application under laboratory conditions [29], test it under field conditions [31], on insecticide-resistance mosquitoes [12-14], and on different substrates such as cloth, netting, wood, clay tiles, and mud walls $[11,17,32]$. In the present study, it has been shown the potential of selecting the most virulent isolate since this can result in an increased effectiveness of up to ten-fold. Such selection should be dependent on the ecological situation at the location of intended use, as using a highly virulent isolate may potentially lead to an increased selection pressure that can result in resistance in mosquitoes [3]. Additionally, genetic diversity of natural populations of mosquitoes have to be taken into consideration, since some genotypes could be more susceptible to fungal infection than others, and this could lead to an increased selective pressure as well [33]. Moreover, it has been shown that there is a dose-dependent effect of spore concentration $[17,29]$, so when comparing a highly lethal to a lethal isolate, the highly lethal isolate could have a similar effect using a lower concentration. Thus, the amount of spores can potentially be reduced, which would lower the application costs. Nevertheless, other factors need to be further considered since virulence is not the only variable that is important when using a fungus as biological control agent. Viability and persistence for example, can be limitations in tropical (malaria-endemic) climates.

It was hypothesized that phenotypic characteristics of $B$. bassiana potentially correlate with virulence in mosquitoes as previous studies have shown that morphological and physiological traits of $B$. bassiana are related to virulence in other insects [24,25,28]. For example, fungal isolates with rapid germination and high hyphal growth rate may be advantageous to use as a biological control agent, because such fungi could infect the host more rapidly [24]. Zhang et al. [28] found a positive correlation between growth rate, sporulation and germination rate of $B$. bassiana with virulence of red turpentine beetle larvae. Nevertheless, in the current study no relationship could be demonstrated between morphological characteristics and the virulence of $B$. bassiana isolates to $A n$. coluzzii. This is consistent with earlier work of Talaei-Hassanloui et al. [26] who did not find any correlation between radial growth rate, spore size, germination or pigmentation and virulence on second instar larvae of Leptinotarsa decemlineata and Plutella xylostella. Ideally, one would like to be able to predict virulence of a fungus from its phenotypic characteristics without conducting bioassays that require many live insects and relatively long experimental duration before results are known. However, no such trend was observed in this study. Therefore, bioassays remain the method of choice to unravel fungal virulence, at least for this fungal-insect system and with this selection of isolates.

The results suggest that other molecular and physiological mechanisms, such as the excretion of chitinases and the ability to avoid and/or counter the insect immune response, could be related to the variation in fungal virulence. Indeed, the wide variation observed in virulence offers a unique opportunity to understand the genetic, molecular and physiological mechanisms that underpin this variation. In $B$. bassiana several proteins have been characterized as relevant for virulence. For instance, proteins of the P450 family have been identified as important for cuticle degradation [34,35], and Bbslt2, a novel mitogen-activated protein (MAP) kinase, was identified to have a crucial role in regulating fungal development, growth and pathogenicity [36]. As well as Bbgas1, a gene encoding a putative transferase (Glycosylphosphatidylinositol-Anchored $\beta-1,3-$ Glucanosyltransferase) is involved in conidial thermotolerance and virulence [37]. Many more genes have also been linked to virulence, which hint that virulence is a complex process regulated by several pathways.

\section{Conclusions}

The results demonstrate that there is much natural variation in virulence of fungal isolates of $B$. bassiana that can be exploited by choosing the most suitable isolate for controlling malaria mosquitoes. This notion makes the use of entomopathogenic fungi an even more viable option, especially if used as part of an integrated vector management strategy. In addition, the natural variation observed in virulence offers the possibility to focus on the genetic mechanisms that determine this variation and would help in understanding the fungal mechanisms of $B$. bassiana towards malaria mosquitoes, and provide evidence that this could be an evolution-proof biological control agent. This is where the current research effort is focusing.

\section{Competing interests}

The authors declare that they have no competing interests.

\section{Authors' contributions}

CAVJ designed the study and performed the experiments. CAVJ and CJMK did the statistical analyses and drafted the manuscript. AJMD, BJZ, JALVK,

SES, and WT contributed to the study design and writing of the manuscript. All authors read and approved the final manuscript.

\section{Acknowledgements}

We would like to thank Sebastiaan Haemers for assistance in spore production. We thank Richard Humber for sending the fungal isolates from 
the ARSEF collection. This research was funded by the Production Ecology \& Research Conservation graduate School grant 12072.

\section{Author details}

'Laboratory of Genetics, Wageningen University, P.O Box 309, 6700, AH Wageningen, The Netherlands. ${ }^{2}$ Laboratory of Entomology, Wageningen University, P.O. Box 8031, 6700, EH Wageningen, The Netherlands. ${ }^{3}$ Laboratory of Phytopathology, Wageningen University, P.O Box 8025, 6700, EE Wageningen, The Netherlands.

Received: 9 July 2014 Accepted: 30 November 2014 Published: 6 December 2014

\section{References}

1. WHO: Malaria. Geneva: World Health Organization; 2013.

2. Kanzok SM, Jacobs-Lorena M: Entomopathogenic fungi as biological insecticides to control malaria. Trends Parasitol 2006, 22:49-51.

3. Thomas MB, Read AF: Can fungal biopesticides control malaria? Nat Rev Microbiol 2007, 5:377-383.

4. Knols BGJ, Bukhari T, Farenhorst M: Entomopathogenic fungi as the next-generation control agents against malaria mosquitoes. Future Microbiol 2010, 5:339-341.

5. Castrillo LA, Griggs MH, Liu H, Bauer LS, Vandenberg JD: Assessing deposition and persistence of Beauveria bassiana GHA (Ascomycota: Hypocreales) applied for control of the emerald ash borer, Agrilus planipennis (Coleoptera: Buprestidae), in a commercial tree nursery. Biol Control 2010, 54:61-67.

6. Lomer C, Bateman R: Biological control of locusts and grasshoppers. Annu Rev Entomol 2001, 46:667-702.

7. Clarkson JM, Charnley AK: New insights into the mechanisms of fungal pathogenesis in insects. Trends Microbiol 1996, 4:197-203.

8. Pedrini N, Crespo R, Juárez MP: Biochemistry of insect epicuticle degradation by entomopathogenic fungi. Comp Biochem Physiol C Toxicol Pharmacol 2007, 146:124-137.

9. St Leger RJ, Joshi L, Roberts D: Ambient pH is a major determinant in the expression of cuticle-degrading enzymes and hydrophobin by Metarhizium anisopliae. Appl Environ Microbiol 1998, 64:709-713.

10. Boomsma JJ, Jensen AB, Meyling NV, Eilenberg J: Evolutionary interaction networks of insect pathogenic fungi. Annu Rev Entomol 2014, 59:467-485.

11. Mnyone LL, Lyimo IN, Lwetoijera DW, Mpingwa MW, Nchimbi N, Hancock PA, Russell TL, Kirby MJ, Takken W, Koenraadt CJM: Exploiting the behaviour of wild malaria vectors to achieve high infection with fungal biocontrol agents. Malar J 2012, 11:87.

12. Farenhorst M, Mouatcho JC, Kikankie CK, Brooke BD, Hunt RH, Thomas MB, Koekemoer LL, Knols BGJ, Coetzee M: Fungal infection counters insecticide resistance in African malaria mosquitoes. Proc Natl Acad Sci U S A 2009, 106:17443-17447.

13. Howard AFV, Koenraadt CJM, Farenhorst M, Knols BGJ, Takken W: Pyrethroid resistance in Anopheles gambiae leads to increased susceptibility to the entomopathogenic fungi Metarhizium anisopliae and Beauveria bassiana. Malar J 2010, 9:168.

14. Howard AFV, N'Guessan R, Koenraadt CJM, Asidi A, Farenhorst M, Akogbéto M, Knols BGJ, Takken W: First report of the infection of insecticide-resistant malaria vector mosquitoes with an entomopathogenic fungus under field conditions. Malar J 2011, 10:24.

15. Blanford S, Chan BHK, Jenkins N, Sim D, Turner RJ, Read AF, Thomas MB: Fungal pathogen reduces potential for malaria transmission. Science 2005, 308:1638-1641.

16. Scholte E-J, Knols BGJ, Takken W: Infection of the malaria mosquito Anopheles gambiae with the entomopathogenic fungus Metarhizium anisopliae reduces blood feeding and fecundity. I Invertebr Pathol 2006, 91:43-49.

17. Blanford S, Shi W, Christian R, Marden JH, Koekemoer LL, Brooke BD, Coetzee M, Read AF, Thomas MB: Lethal and pre-lethal effects of a fungal biopesticide contribute to substantial and rapid control of malaria vectors. PLoS One 2011, 6:e23591.

18. George J, Blanford S, Domingue MJ, Thomas MB, Read AF, Baker TC: Reduction in host-finding behaviour in fungus-infected mosquitoes is correlated with reduction in olfactory receptor neuron responsiveness. Malar J 2011, 10:219.
19. Killeen GF, McKenzie FE, Foy BD, Schieffelin C, Billingsley PF, Beier JC: A simplified model for predicting malaria entomologic inoculation rates based on entomologic and parasitologic parameters relevant to control. Am J Trop Med Hyg 2000, 62:535-544.

20. Read AF, Lynch P, Thomas MB: How to make evolution-proof insecticides for malaria control. PLoS Biol 2009, 7:e1000058.

21. Rehner SA, Minnis AM, Sung G-H, Luangsa-ard JJ, Devotto L, Humber RA: Phylogeny and systematics of the anamorphic, entomopathogenic genus Beauveria. Mycologia 2011, 103:1055-1073.

22. Blanford S, Jenkins NE, Christian R, Chan BHK, Nardini L, Osae M, Koekemoer L, Coetzee M, Read AF, Thomas MB: Storage and persistence of a candidate fungal biopesticide for use against adult malaria vectors. Malar J 2012, 11:354.

23. Howard AF, N'guessan R, Koenraadt CJ, Asidi A, Farenhorst M, Akogbéto M, Thomas MB, Knols BG, Takken W: The entomopathogenic fungus Beauveria bassiana reduces instantaneous blood feeding in wild multi-insecticide-resistant Culex quinquefasciatus mosquitoes in Benin. West Africa Parasit Vectors 2010, 3:87.

24. Liu H, Skinner M, Brownbridge M, Parker BL: Characterization of Beauveria bassiana and Metarhizium anisopliae isolates for management of tarnished plant bug, Lygus lineolaris (Hemiptera: Miridae). J Invertebr Pathol 2003, 82:139-147.

25. Varela A, Morales E: Characterization of some Beauveria bassiana isolates and their virulence toward the coffee berry borer Hypothenemus hampei. J Invertebr Pathol 1996, 152:147-152

26. Talaei-Hassanloui R, Kharazi-Pakdel A, Goettel M, Mozaffari J: Variation in virulence of Beauveria bassiana isolates and its relatedness to some morphological characteristics. Biocontrol Sci Technol 2006, 16:525-534.

27. Quesada-Moraga E, Vey A: Intra-specific variation in virulence and in vitro production of macromolecular toxins active against locust among Beauveria bassiana strains and effects of in vivo and in vitro passage on these factors intra-specific var. Biocontrol Sci Technol 2003, 13:323-340.

28. Zhang L-W, Liu Y-J, Yao J, Wang B, Huang B, Li Z-Z, Fan M-Z, Sun J-H: Evaluation of Beauveria bassiana (Hyphomycetes) isolates as potential agents for control of Dendroctonus valens. Insect Sci 2011, 18:209-216.

29. Farenhorst M, Knols BGJ: A novel method for standardized application of fungal spore coatings for mosquito exposure bioassays. Malar J 2010, 9:27.

30. Davis R, de Serres F: Genetic and microbiological research techniques for Neurospora crassa. Methods Enzymol 1970, 17:79-143.

31. Scholte E-J, Ng'habi K, Kihonda J, Takken W, Paaijmans K, Abdulla S, Killeen GF, Knols BGJ: An entomopathogenic fungus for control of adult African malaria mosquitoes. Science 2005, 308:1641-1642.

32. Mnyone LL, Kirby MJ, Lwetoijera DW, Mpingwa MW, Simfukwe ET, Knols BGJ, Takken W, Russell TL: Tools for delivering entomopathogenic fungi to malaria mosquitoes: effects of delivery surfaces on fungal efficacy and persistence. Malar J 2010, 9:246.

33. Mitri C, Vernick KD: Anopheles gambiae pathogen susceptibility: the intersection of genetics, immunity and ecology. Curr Opin Microbiol 2012, 15:285-291.

34. Zhang S, Widemann E, Bernard G, Lesot A, Pinot F, Pedrini N, Keyhani NO: CYP52X1, representing new cytochrome P450 subfamily, displays fatty acid hydroxylase activity and contributes to virulence and growth on insect cuticular substrates in entomopathogenic fungus Beauveria bassiana. J Biol Chem 2012, 287:13477-13486.

35. Pedrini N, Zhang S, Juárez MP, Keyhani NO: Molecular characterization and expression analysis of a suite of cytochrome P450 enzymes implicated in insect hydrocarbon degradation in the entomopathogenic fungus Beauveria bassiana. Microbiology 2010, 156:2549-2557.

36. Luo X, Keyhani NO, Yu X, He Z, Luo Z, Pei Y, Zhang Y: The MAP kinase Bbslt2 controls growth, conidiation, cell wall integrity, and virulence in the insect pathogenic fungus Beauveria bassiana. Fungal Genet Biol 2012, 49:544-555.

37. Zhang S, Xia Y, Keyhani NO: Contribution of the gas1 gene of the entomopathogenic fungus Beauveria bassiana, encoding a putative glycosylphosphatidylinositol-anchored beta-1,3-glucanosyltransferase, to conidial thermotolerance and virulence. Appl Environ Microbiol 2011, 77:2676-2684.

doi:10.1186/1475-2875-13-479

Cite this article as: Valero-Jiménez et al:: Natural variation in virulence of the entomopathogenic fungus Beauveria bassiana against malaria mosquitoes. Malaria Journal 2014 13:479. 